\title{
Pathogenicity of Helicobacter pylori in cancer development and impacts of vaccination
}

\author{
Hadi Maleki Kakelar ${ }^{1} \cdot$ Abolfazl Barzegari $^{1} \cdot$ Jaber Dehghani $^{1} \cdot$ Shahram Hanifian $^{2} \cdot$ Nazli Saeedi $^{1} \cdot$ Jaleh Barar $^{1,3}$. \\ Yadollah Omidi ${ }^{1,3}$
}

Received: 12 June 2018 / Accepted: 14 August 2018 / Published online: 25 August 2018

(c) The International Gastric Cancer Association and The Japanese Gastric Cancer Association 2018

\begin{abstract}
Helicobacter pylori affect around 50\% of the population worldwide. More importantly, the gastric infection induced by this bacterium is deemed to be associated with the progression of distal gastric carcinoma and gastric mucosal lymphoma in the human. H. pylori infection and its prevalent genotype significantly differ across various geographical regions. Based on numerous virulence factors, $H$. pylori can target different cellular proteins to modulate the variety of inflammatory responses and initiate numerous "hits" on the gastric mucosa. Such reactions lead to serious complications, including gastritis and peptic ulceration, gastric cancer and gastric mucosa-associated lymphoid structure lymphoma. Therefore, $H$. pylori have been considered as the type I carcinogen by the Global Firm for Research on Cancer. During the two past decades, different reports revealed that $H$. pylori possess oncogenic potentials in the gastric mucosa through a complicated interplay between the bacterial factors, various facets, and the environmental factors. Accordingly, numerous signaling pathways could be triggered in the development of gastrointestinal diseases (e.g., gastric cancer). Therefore, the main strategy for the treatment of gastric cancer is controlling the disease far before its onset using preventive/curative vaccination. Increasing the efficiency of vaccines may be achieved by new trials of vaccine modalities, which is used to optimize the cellular immunity. Taken all, H. pylori infection may impose severe complications, for resolving of which extensive researches are essential in terms of immune responses to $H$. pylori. We envision that $H$. pylori-mediated diseases can be controlled by advanced vaccines and immunotherapies.
\end{abstract}

Keywords Helicobacter pylori $\cdot$ Virulence factors $\cdot$ Gastric cancer $\cdot$ Host factors $\cdot$ Molecular mechanisms $\cdot$ Vaccination

\section{Introduction}

Helicobacter pylori bacterium is one of the most common human infectious agents around the globe. Genetic sequencing evaluation suggested that human and $H$. pylori have been co-evolved for a very long time [1]. Since its discovery in 1982, H. pylori bacteria have directly been associated with a range of gastrointestinal conditions [2]. Currently, it is

Yadollah Omidi

yomidi@tbzmed.ac.ir

1 Research Center for Pharmaceutical Nanotechnology, Biomedicine Institute, Tabriz University of Medical Sciences, Tabriz, Iran

2 Department of Food Science and Technology, Tabriz Branch, Islamic Azad University, Tabriz, Iran

3 Department of Pharmaceutics, Faculty of Pharmacy, Tabriz University of Medical Sciences, Tabriz 5165665811, Iran believed that $H$. pylori is the most frequent etiologic agent involved in the infection-associated cancers, which holds $5.5 \%$ of the cancer burden in the worldwide [3]. The prevalence of $H$. pylori is dependent on several factors, including geographical region, socioeconomic position, educational level, background and residing setting and lifestyle [4].

Two regular insufferable neoplasms started in the stomach include (i) adenocarcinoma and (ii) lymphoma of gastric, the so-called mucosa-associated lymphoid tissue (MALT). Although the possibility of gastric carcinoma infection has declined in some countries, this disease is considered as the major reason for the cancer-related demise in the world [3]. Unfortunately, many gastric cancers (GCs) are diagnosed in the advanced stages, so that the treatment of these diseases are rarely achieved by surgery and adjuvant therapy approaches [5, 6]. Gastric carcinomas and MALT lymphomas seem to occur in a setting of chronic gastric inflammation [7]. However, in the two past decades, the most 
common reason for gastritis was shown to be induced by the consistent $H$. pylori infection. It should be noted that almost $70 \%$ of global gastric cancer and gastric MALT lymphomas incidences are happening by the previous infection with $H$. pylori $[6,8]$.

Altogether, among different diseases that strongly linked to $H$. pylori infection, gastrointestinal malignancies remain as one of the most life-threatening ailment that require a better understanding of the molecular mechanism(s) involved with the initiation and progression of the disease. Hence, in this review, we present some important mechanistic insights into the involvement of $H$. pylori in gastric carcinogenesis and the impacts of passive and active vaccinations.

\section{A glance at the pathogenesis of $H$. pylori}

H. pylori is a Gram-negative spiral-shaped bacterium (Fig. 1) acquired often in the human infancy that can induce chronic gastric inflammation during human life, which is also the most crucial riskiness factor for gastric malignancies
[9]. The impacts of $H$. pylori infection on the gastric malignancies might depend on the anatomic location [10]. However, gastroesophageal junction cancer might be associated with either $H$. pylori infection or Barrett's esophagus [11]. Therefore, the abolition of $H$. pylori has become a typical treatment modality in people with the gastric MALT lymphoma. Because $H$. pylori do not adhere effectively to the abdominal mucosal cells, linking this infection to the intestinal type gastric cancer may not be obvious when the intestinal metaplasia dominates the gastric topography. For the same reasons, serum antibody levels against $H$. pylori antigens decrease during the development of gastric cancer [12]. Although $H$. pylori mostly adhere to the epithelial cells of the stomach, it may also colonize at the proximal duodenum resulting in a possible transformation of gastric tissue (the so-called metaplasia).

Accordingly, it has been articulated that the intracellular presence of $H$. pylori may promote its persistence, resulting in the induction of an inadvertent antibiotic resistance [13]. H. pylori utilize its very effective enzymatic pieces of machinery (e.g., urease) to buffer the gastric environment with pH 1-2 acidity [14]. Furthermore, the survival of

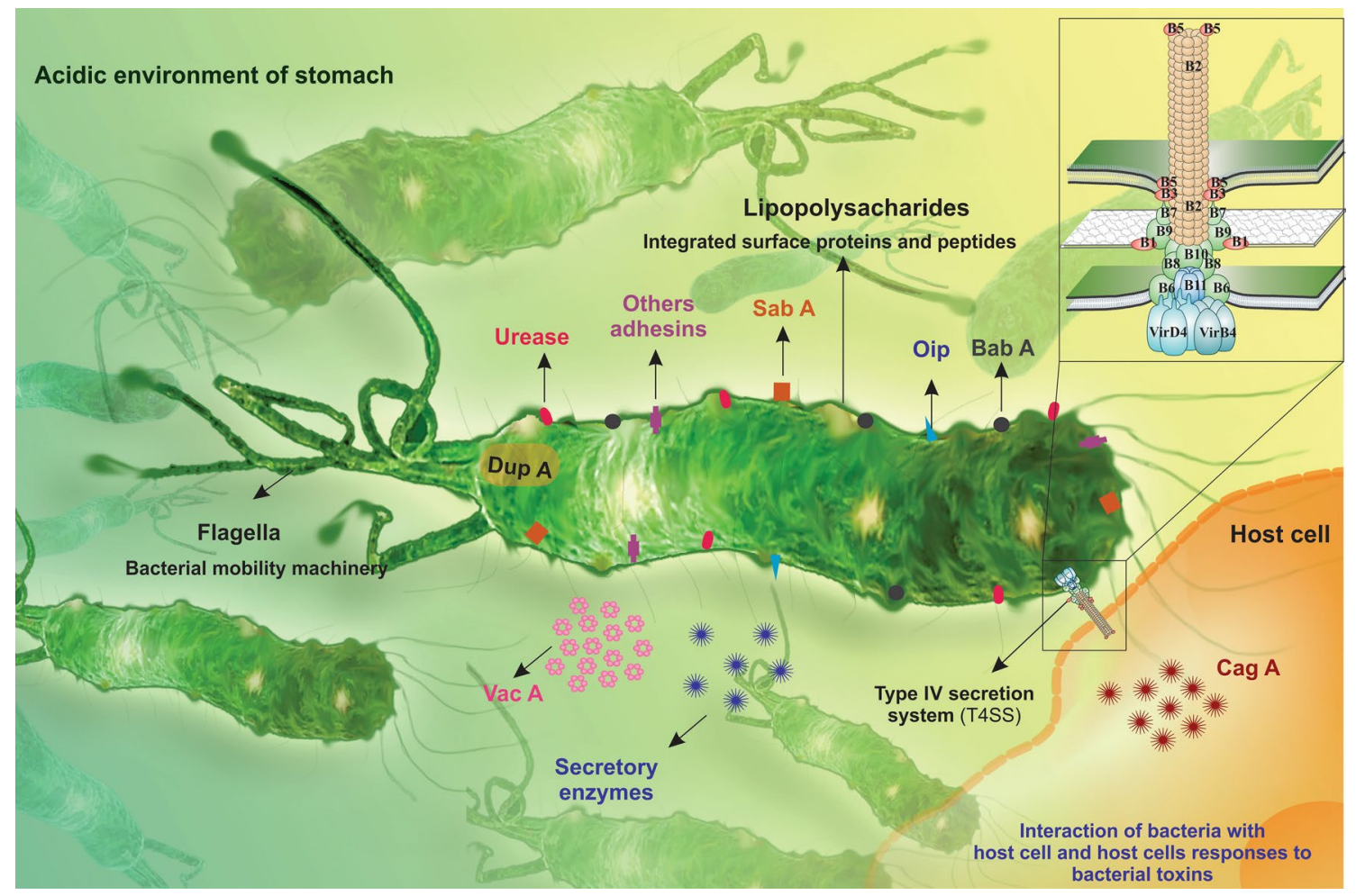

Fig. 1 Helicobacter pylori structure and its infection mechanism. Various bacterial entities (e.g., toxins and enzymes) are involved in the interaction of bacteria with the host cells and its evasion from the immune system surveillance. Flagella gives motility and enables the bacterium to grow under the mucosal membrane. LPS lipopolysaccharides and membrane proteins adhere to the host cell recep- tors. Urease enzyme is used to combat the acidic environment of the stomach by producing ammonia. VacA exotoxin causes injury to the mucosal membrane. T4SS Type IV secretion system that uses a pillus to inject effectors (inset). CagA causes actin remodeling and inhibits apoptosis. Outer proteins (BabA, Oip, SabA, Others adhesins) adhere to the host cells 
bacteria is facilitated by the helical morphology and unipolar flagella permitting movement within the gastric mucous layer via overlaying among and/or within the gastric epithelial cells (Fig. 1) [15].

\section{Genomics of $\boldsymbol{H}$. pylori}

Variations of the H. pylori genome is significantly associated with the migration trends of human populations, which connecting the geographical dissemination of the microorganism leading to the emergence of mankind life [16]. $H$. pylori genome was sequenced in 1997 [17] and since then several full genome sequences (at least 7) have been reported [17-22]. Generally, the H. pylori genome comprises about 1.6 megabases, encoding approximately 1500 predicted open reading frames (ORFs) and about $20-30 \%$ genomic variation among different strains. This issue is relatively high percentage of bacterial species, resultant from the high spontaneous mutation rate and recombination frequency within the microorganism genome [23]. Several variable regions within the $H$. pylori genome have already been identified, including "plasticity zone" and "cytotoxin-associated gene" ( $\mathrm{Cag}$ ) pathogenicity island. The $\mathrm{Cag}$ island encodes a few structural proteins that required for assembling four secretion systems, effective on the translocation of the H. pylori products (e.g., immune dominant 120-145 kDa CagA protein) [24] within the host gastric epithelial cells [25]. The H. pylori genome also encodes several adhesion proteins that are important for ensuring tight contact between $H$. pylori and gastric epithelial cells. These proteins include the blood group antigen binding adhesin $(B a b A)$ and the sialic acid binding adhesin, SabA. VacA gene of $H$. pylori encodes a multimeric vacuolating secretory cytotoxin $(88$ $\mathrm{kDa}$ ), which is effective for developing the intracellular vacuoles in the gastric and different epithelial cells [26]. This gene is conserved among all $H$. pylori strains. Nevertheless, the gene exhibits a high level of genetic variation within regions that encode the signal sequence, intermediate factor, and the middle portion of the $V a c A$ protein [27]. The recent evaluation of the transcriptome of $H$. pylori strain 26,695 has revealed that the simultaneous presence of sense and antisense transcripts from common RNA sequences within the organism [28], introducing another level of complexity of the genome. Multiple RNAs forms such as non-coding RNAs were also reported within the H. pylori.

\section{H. pylori pathogenesis in GC}

H. pylori produce many different virulence factors that may dysregulate the host intracellular signaling mechanism(s) and promote the neoplastic transformation [29]. Among those, $\operatorname{CagA}$ and its pathogenicity region ( $\mathrm{Cag} \mathrm{PAI}$ ), and VacA (vacuolating cytotoxin A) are deemed as the significant pathogenic factors, which will be discussed in the following sections (Fig. 2) [24].

\section{Impacts of CagA in GC}

The Cag PAI is a $40 \mathrm{~kb}$ locus comprising $27-31$ genes. A few genes within this locus encode the $\operatorname{CagA}$ protein and the Cag type IV secretion process (T4SS) [30]. Of these, the T4SS forms a syringe-like pilus structure, through which the CagA protein can be injected into the host cells, leading to the modulation of cellular processes in the favor of the pathogenic activity of an invader. For such phenomena, the ectodomain of a $5 \mathrm{~b} 1$ integrin seems to be a vital step for the translocation of $\mathrm{CagA}$ into the host cells [31]. Subsequently, CagA binds to the internal surface of the cell membrane and undergoes tyrosine phosphorylation at glutamate-proline-isoleucine-tyrosine-alanine (EPIYA) site by Src family kinases. It should be noted that the phosphorylated and unphosphorylated $\mathrm{CagA}$ interact with numerous host proteins, resulting in the activation of some downstream signaling pathways, including the Ras/mitogen-activated protein kinase (MEK), extracellular signal-regulated kinase (ERK) $[32,33]$, nuclear element $\mathrm{\kappa B}$ (NF-кB), and $\beta$-catenin pathways. These biological functions appear to enhance the proliferative ability of the gastric epithelial cells (Fig. 2) [34].

\section{Impacts of VacA in GC}

H. pylori secrete the vacuolating cytotoxin $(\operatorname{Vac} A)$ via a type $\mathrm{V}$ auto transport release system [24]. VacA is an 88 $\mathrm{kDa}$, constituting p33 and $\mathrm{p} 55$ subunits, in which the p33 protein $(\mathrm{N}$-terminal, $33 \mathrm{kDa})$ forms an inner channel for the chloride transportation and the 555 protein $(\mathrm{C}$-termi$\mathrm{nal}, 55 \mathrm{kDa}$ ) is responsible for the presentation of toxin into the host cells [35]. VacA has several biological activities, and it can bind to a variety of cells. After the internalization, it can induce intense vacuolation by the accumulation of large vesicles existed in both early and late endosomes. VacA can be transferred to the mitochondria, in which it causes the dissipation of mitochondrial transmembrane potential $\left(\Delta \Psi_{\mathrm{m}}\right)$, discharge of cytochrome $\mathrm{c}$, and the activation of pro-apoptotic factor Bcl-2 associated $\mathrm{X}$ protein (Bax). All these proteins can eventually involve in the apoptosis [36]. During VacA-induced mitochondria perturbation, the activation of dynamin-related protein 1 (DRP1) may play a critical role because the inhibition of DRP1-dependent mitochondria fission within the VacAintoxicated cells was shown to inhibit the activation of Bax and mitochondrial outer membrane permeabilization 


\section{Interaction of $H$. pylori with the gastric epithelial cells}

a Interaction of urease with host cells

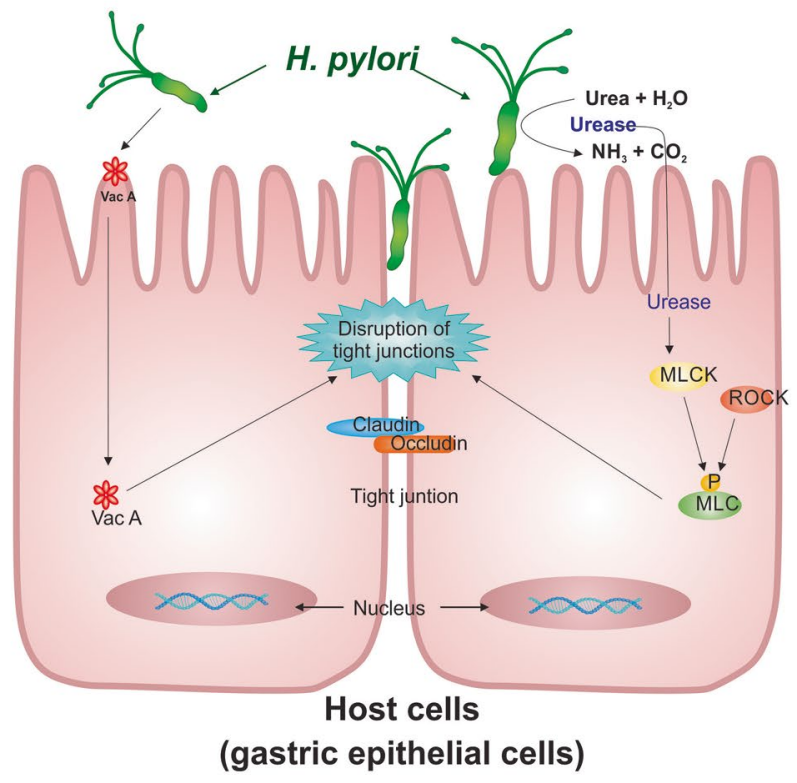

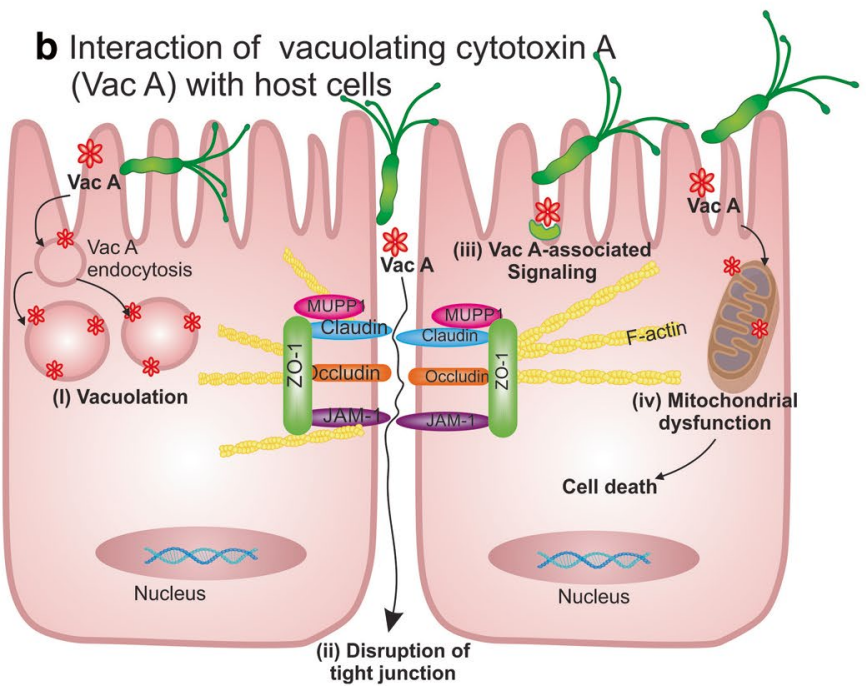

Fig. 2 Dysregulation of the apical-junctional complex by $H$. pylori. a Released and imported urease can phosphorylate MLC by MLCK kinase, leading to the disruption of tight junctions between the stomach cells. b Vacuolating cytotoxin A (VacA) is secreted by the bacteria, which can then bind to host cells. Once internalized by the host gastric epithelial cells, VacA can induce a severe vacuolation - seen as the accumulation of large vesicles similar to early and late endosomes, and early lysosomes. The development of "vacuoles" has been attributed to the formation of VacA anion-selective channels in membranes. Besides, the p33 subunit of VacA can enter into the

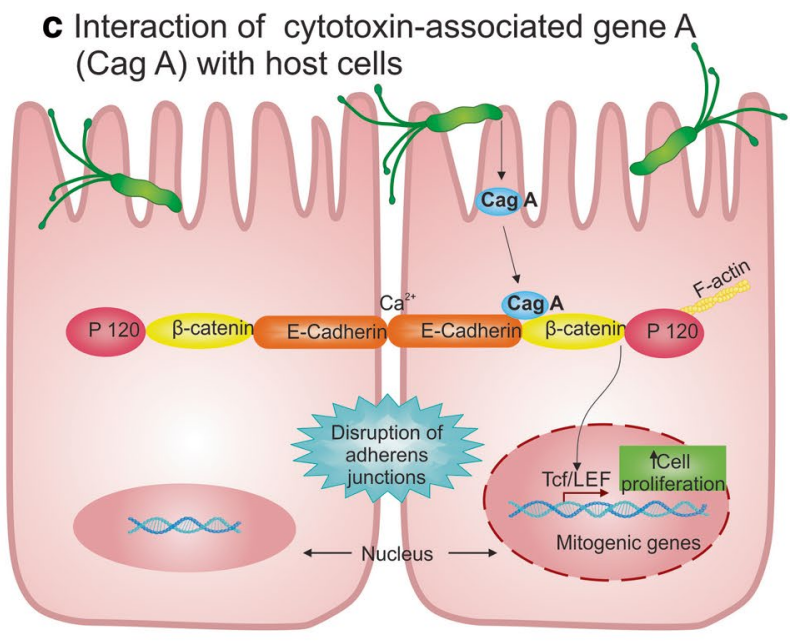

mitochondria and disrupt their function. Moreover, VacA by effecting on the tight junction elements such as occludin, claudin and JAM-1 can disrupt the junctions between the stomach cells. c After importing the $\operatorname{CagA}$ into the stomach cells, it can physically interact with the E-cadherin, releasing of and importing $\beta$-catenin into the nucleus. $H$. pylori can induce the nuclear translocation of $\mathrm{p} 120$ protein, which can increase the releasing level of $\beta$-catenin. In the nucleus, $\beta$-catenin can induce the accumulation of the tcf/LEF and subsequently the highly increasing the cell proliferation

the disruption of the autophagy could be considered as another mechanism by which $V a c A$ causes gastric inflammation, and hence, contributes to gastric carcinogenesis (Fig. 2) [38, 39]. 


\section{H. pylori responses and its role in the induction of GC}

H. pylori infection and the resultant chronic inflammation in the gastric mucosa is believed to be the major part of the initiation, development, and progression of GC. In fact, $H$. pylori bacteria stimulate an inflammatory response both in the gastric epithelial cells and the immune cells recruited to the site of infection through multiple mechanisms [40]. It has been shown that the $H$. pylori infection upregulates the functional expression of several pro-inflammatory cytokines such as interleukin (IL) 1, IL-6, IL-8, tumor necrosis factor $\alpha$ (TNF- $\alpha)$, NF-кр, and also regulates the activation of regular $\mathrm{T}$ cells [40]. These cytokines, particularly NF-кB, are key mediators of gastric pathophysiology and may perform important roles in the development of gastric inflammation and cancer (Fig. 3).

\section{Role of CSCs in $\mathrm{H}$. pylori-induced gastric inflammation and carcinogenesis}

Cancer stem cells (CSCs) are considered as a special set of cells with the self-renew ability for the differentiation to mature tumor cells [41]. Recently, it is thought that CSCs perform a pivotal role in the development of several cancers such as GC [42]. Although the origin of the gastric CSCs is not absolutely clear, it is believed that they originate from the segregated gastric epithelial cells,



Fig. 3 Schematic view of $H$. pylori infection and the induction of matrix metalloproteinases (MMPs) involved with both cellular and humoral components. a Cellular responses. During the infection of H. pylori, CagA with type IV Secretion System (TSSIV) enter into the gastric epithelial cells. CagA phosphorylation occurs by host's $S r c / A b l$ kinases and the phosphorylated CagA activates a series of signaling molecules such as inflammatory cytokines, ROS, MMPs, leading the aberrant cellular function. b Humoral responses. H. pylori prime the host immune system by various lymphocyte sub- sets through dendritic cells (DC)-mediated antigen presentation to the naive $\mathrm{T}$ cell. Under the influence of specific cytokines and foreign antigens, the naive $\mathrm{T}$ cells start switching and differentiate into the effector T subtypes via signature transcription factors. TH17 and TH1 promote the inflammatory response while Treg arrests the reactions by secreting immunosuppressive cytokines; and thereby, maintaining H. pylori inside the gastric mucosa. TH17 stimulates MMPs through IL-17 and IL-21 
local progenitor cells in the gastric mucosa, or bone marrow-derived cells (BMDCs) [43]. Some in vivo animal studies have demonstrated that the chronic inflammation could induce gastric CSCs, resulting in $\mathrm{H}$. pylori-induced GC [44]. Intriguingly, some virulence factors of $H$. pylori (e.g., CagA protein, T4SS or VacA protein) might not be involved in the mobilization of gastric CSCs, but rather, the certain undiscovered virulence factors and cytokines secreted by contaminated epithelial cells (e.g., TNF- $\alpha$ ) could be involved in this process [44]. The role of BMDCs in $H$. pylori-induced gastric carcinogenesis has recently been reported, showing that the strains of $H$. pylori were able to recruit bone marrow stem cells to the gastric mucosa via different capacities, upon which they could turn into the gastric glands with the possibility to evolve towards metaplasia and dysplasia [45].

\section{Mechanisms of $\boldsymbol{H}$. pylori-induced gastric carcinogenesis}

The chronic inflammation is stimulated by the persistent H. pylori infection, which can create a permissive microenvironment with the plethora of inflammatory cytokines as well as reactive oxygen and nitrogen species (ROS and RNS) that have the potential to induce cellular damage and mutagenesis [46]. Accelerated cell turnover in such microenvironment can result in (a) the emergence of cell lineages which are not normally found in the stomach (gastric metaplasia) and in a small part of humans infected chronically by $H$. pylori, and (b) the development of neoplastic clones under the pressure of accelerated DNA replication [47]. As such, the chronic inflammatory state is deemed to be the feature of several common individual malignancies, especially in the gastrointestinal tract. Other such examples include chronic acid reflux esophagitis (predisposing to Barrett's metaplasia and esophageal adenocarcinomas), chronic viral hepatitis (increasing the danger of hepatocellular cancer) and the chronic colonic inflammation of the inflammatory bowel diseases (IBD) that are associated with the increased risk of colon cancer [48].

Some investigations focusing on pro-inflammatory immune responses against $H$. pylori infection have mainly been designed based on in vitro models using gastric epithelial AGS cells. Further, it is critical to define the modulating mechanisms of the antigen presenting cells such as dendritic cells (DCs) as well as B and T lymphocytes by $H$. pylori. Given the interactions between pathogen and gut-associated immune cells, it is envisioned that DCs play a major role, through Toll-like receptors (TLRs), in the regulation of the responses of the adaptive immune against $H$. pylori [49] (Fig. 3).

\section{H. pylori-induced changes in epithelial gene expression and regulation}

Of numerous alterations induced by $\mathrm{H}$. pylori in the gastric epithelial cells, the differential expression of various gene clusters plays vital roles in promoting gastric epithelial cell transformation [50]. Although TP53 mutation is one of the common molecular hallmarks of various malignancies, there are inconsistent studies about the regulation of wild-type p53 appearance by $H$. pylori during the pre-neoplastic stages in GC [50]. Nevertheless, the p73, a homologous of p53 protein, has recently been shown to be highly responsive to $H$. pylori, which seems to be much more important than p53 in regulating apoptotic phenomena within the gastric epithelial cells [51].

H. pylori infection has a causal role in the induction of specific alterations on the DNA methylation patterns in the gastric mucosa of $H$. pylori-infected patients and GC cell lines [52]. Of these genes that specifically methylated by $H$. pylori infection, the E-cadherin (CDH1) has a specific importance in the diffuse type of gastric carcinogenesis. In fact, germline mutations in $\mathrm{CDH} 1$ are responsible for the syndrome of hereditary diffuse GC and commonly acquire in the sporadic diffuse type of GC [53]. It should be noted that the methylation of the E-cadherin promoter is reverted to the normal state after the eradication of $H$. pylori [54]. H. pylori infection also causes hypermethylation leading to a decrease in the expression of DNA repair protein O-6-methylguanine-DNA methyltransferase. The latter enzyme is a biomolecule, which is normally involved in the prevention of cytosine: guanine to adenine: thymine change mutations, and thus, DNA replication fidelity [55].

Several groups have recently analyzed the microRNA signatures of the H. pylori infection and showed that the dysregulation of miRNA expression could be mechanistically linked between the $H$. pylori infection and the development of gastric malignancies [56]. Furthermore, a study of the differential expression of microRNAs between $H$. pylori-positive and negative patients showed that 14 of 30 miRNAs after $H$. pylori eradication were repaired [57]. Further, the upregulation of certain miRNAs such as the members of let-7 family is affected in the presence of the Cag pathogenicity island. However, miR 21 and miR 155 could be upregulated during the occurrence of $H$. pylori infection, which may provide some insights about the significance of these markers in vivo [58-60]. 


\section{Loss of gastric acidity}

H. pylori bacteria are one of the bacterial species that can efficiently survive in an extreme condition $(\mathrm{pH} 2-3)$ of the gastric lumen. The resident bacteria in the oral cavity and gastrointestinal regions can be colonized in the stomach if the gastric $\mathrm{pH}$ reaches to $\mathrm{pH} 7$. The chronic gastric inflammation may be predisposed to GC through atrophy of gastric glands due to the lack of the specialized acid-secreting parietal cells [61]. In the state of hypochlorhydria, the colonization and growth of non-Helicobacter species may generate carcinogenic and potentially genotoxic nitrosamines [62]. It should be noted that the interplay between $H$. pylori infection, gastric acid secretion and clinical outcome is complicated, which is dependent on a large region within the stomach with maximal $H$. pylori infection. For instance, despite being infected by $H$. pylori, individuals who involved with the duodenal ulcers showed high acid secretory rates, while they had a very small chance of developing GC [63]. Such discrepancy seems to be explicable on the foundation of $H$. pylori infection in such patients being solely confined to the gastric antrum rather than other regions. Such infection may result in the depletion of the somatostatin secreting cells in the region and eliciting a subsequent exaggerated release of the acid secretory hormone gastrin from the particular antral gastrin-secreting neuroendocrine cells. When the proximal stomach has not infected with $H$. pylori, in duodenal ulcer patients, the high levels of gastrin can stimulate the healthy parietal cells of the proximal stomach towards hypersecretion gastric acid, causing inevitable ulcerative damages in the proximal duodenum [64]. Although some patients have high levels of gastrin, their parietal cells present an intriguing hyper-functional environment of intense proximal stomach inflammation and consequently glandular atrophy of $\mathrm{H}$. pylori-induced inflammation [65].

\section{Role of oxidative stress and DNA damage in $\mathrm{H}$. pylori-induced gastric inflammation and carcinogenesis}

The pathogenesis of $H$. pylori-associated gastric carcinogenesis appears to be associated with the generation of intracellular ROS RNS in the human stomach, as well as the oxidative stress and DNA damages (e.g., p53) [66, 67]. It is demonstrated that $H$. pylori can induce the generation of ROS and RNS in the host gastric epithelial cells and inflammatory cells (e.g., neutrophils) [68], indicating their important roles in the gastric carcinogenesis.

\section{Gastric immune response to infection}

In the absence of $H$. pylori antigenic stimulation, the stomach appears to act as a relatively quiescent organ with little evidence of immunologic activity. Further, an oral immunization that supports the trafficking and migration of antigens into the mucosal organs of antigen-specific T cells and IgA $\mathrm{B}$ cells may result in originating in the gut-associated lymphoid tissues (GALT). So that, the uninfected stomach is segregated from the continuous entry of lymphocytes into the mucosal sites $[69,70]$. These findings indicate a paucity of local gastric cytokines and chemokines involved in guiding integrin expression, leukocyte homing, and an influx in the absence of $H$. pylori-driven inflammation. Early events during binding $H$. pylori to the gastric epithelial cells are mediated by the interaction of epithelial cell glycoconjugate and integrin receptors with their cognate $H$. pylori ligands [71-74]. Adhesion reaction induces the translocation of $H$. pylori protein antigens into the epithelial cells by type IV secretion [75] and the focal reorganization of cytoskeletal proteins into the membrane pedestals [76]. Tyrosine phosphorylation of the host proteins leads to the activation of $\mathrm{NF}-\mathrm{\kappa B}$ transcription factor than promoting the production of inflammatory cytokines and chemokines [77, 78]. Accordingly, gastric biopsies from the infected subjects exhibit the increased levels of several factors, including interleukin- $1 \beta$ (IL-1 $\beta$ ), IL-6, IL-8, IL-12, tumor necrosis factor alpha (TNF- $\alpha$ ), growth-related oncogene, monocyte chemotactic protein-1, macrophage inflammatory protein-1 alpha, and regulated-upon-activation $\mathrm{T}$ expressed and secreted (RANTES) chemokines [79]. The chemical gradients created by these molecules can be harmonized the expression of cell adhesion receptor-ligand pairs and favor the leukocyte recruitment, accumulation, and activation (Fig. 3).

It is clear that during the infection of gastric tissues, $H$. pylori upregulates the expression of the $\mathrm{CD} 11 \mathrm{~b} / \mathrm{CD} 18$ integrin and its receptor and intercellular-adhesion molecule-1 (ICAM-1; CD54) used for the leukocyte transmigration into inflammatory sites [80-82]. H. pylori can also increase the expression of CD80 and CD86 in gastric epithelial cells [83] required for the costimulation $\mathrm{T}$ cells and the upregulation of class II major histocompatibility complex (MHC) in vivo $[84,85]$. Importantly, the class II of MHC heterodimer may itself act as a receptor for $H$. pylori [86].

\section{Immune evasion strategies employed by $H$. pylori}

To explain its persistence in human populations, $H$. pylori has been suggested either to tolerize the host from mounting a protective immune response or to interfere with the 
immune responses that would otherwise result in its elimination [87]. While the carriage of the H. pylori does not induce peripheral tolerance, several studies indicated the ability of $H$. pylori to downregulate the T-cell proliferation [88] and IL-15 transcription [89] and also to restrict the cognate interactions in the T-cell activation through the perturbation of endocytosis and antigen processing [90]. Recent findings showed that the persistence of $H$. pylori might also be related to its capacity to inhibit $\mathrm{T}$ cells by the induction of apoptosis through Cag pathogenicity island (PAI) and the expression of Fas ligand and evade the immunosurveillance [91]. H. pylori can polarize the host cells and $\mathrm{T}$ cells and alter their responses. Given that the H. pylori infection is dominated by the regulatory $\mathrm{T}$ cells and $\mathrm{T}$ helper 1 (Th1) cells through induced Th17 and the expression of IL-17 and IFN- $\gamma[92,93]$, its immunization may be observed as a type of Th1-dominant response that is in favor of the bacterial growth and progression.

\section{Vaccines}

Vaccines have been developed against a large number of infectious and non-infectious diseases [94]. Early attempts focused on the recombinant urease showed some promising outcomes in animals, nevertheless, some subsequent clinical trials were hampered by a number of certain side effects of mucosal adjuvants [95]. More recently, an intramuscularly administered trivalent vaccine (recombinant CagA, VacA, and neutrophil-activating protein) was developed, while unfortunately the antigens were recognized by the host's cellular and humoral immune systems, causing no immunity in a challenged model [96]. Chen et al. synthesized an $H$. pylori oipA DNA construct, as a therapeutic vaccine, that was delivered by attenuated Salmonella typhimurium in the C57BL/6 mouse model with H. pylori strain SS1 infection [97]. To increase the expression level, the oipA gene was codon-optimized for the mammalian cell systems, resulting in a 2-log reduction of $H$. pylori colonization with sterilizing immunity achieved in three out of 10 mice. The LPS of $H$. pylori is relatively nontoxic but may promote autoimmune responses. Considering the potential of polysaccharide-based conjugate vaccines, Altman et al. chemically modulated the LPS of $H$. pylori by delipidation and conjugation processes to enhance the immunogenicity [98]. Prophylactically administering of the oipA antigen induced enhanced antibody responses and a modest reduction in gastric $H$. pylori loading. Two groups of tested $H$. pylori antioxidant proteins in the mouse models demonstrated the partial protection for both alkyl hydroperoxide reductase (AhpC) [99] and a trivalent superoxide dismutase/catalase/thiol peroxidase preparation [100]. The $A h p C$ was found to be beneficial when administered subcutaneously with alum, while the trivalent vaccine was successful intranasally with the cholera toxin. Moreover, mannosylation could generally improve the antigen presentation, nonetheless, the protection afforded by mannosylated $A h p C$ was no better than that of the native protein [99]. Recently, based on the relative immunodominance of $H$. pylori, the Lpp20 outer membrane lipoprotein in the immunized rabbit antiserum was used to prime BALB/c mice with the recombinant Lpp20 [101]. Then, splenic T-cell responses were analyzed to eight peptides predicted in silico as Lpp20 epitopes. Two of these epitopes showed immunogenicity through the proliferation and cytokine secretion assays. Furthermore, some researchers used restricted HLA and evaluated their immunogenicity effects. Based on the results obtained from murine studies of a multi-T-cell epitope construct against urease $\mathrm{B}$, dominant UreB T-cell epitopes were identified in two H. pylori-infected patients [102]. Each subject revealed the dominant HLA-restricted T-cell responses to different regions of UreB identified by the peptide stimulation in vitro. However, the applicability and practicality of this approach and the development of haplotype-specific vaccine remain to be determined. The same group [103] used a multi-T-cell epitope pseudo protein containing 17 putative $H p a A$, UreB, and $C a g A$ epitopes. Once administered prophylactically subcutaneously in BALB/c mice, the colonization was decreased by $1-2 \operatorname{logs}$. Despite the modestly improving parameters of humoral and cell-mediated immunity, none of the four tested adjuvants could significantly enhance the vaccine efficacy. It was reported that a single epitope of urease A, given intragastrically as a 20-mer peptide with cholera toxin $B$ as an adjuvant, achieved a 1-log reduction in $\mathrm{BALB} / \mathrm{c}$ mice administered either prophylactically or therapeutically [104]. Identifying the optimal adjuvant/ delivery strategy is critical for the clinical trials. Given that cholera toxin and Escherichia coli LT antigen can induce diarrhea in humans, a recently developed LT double mutant (R192G/L211A) was tested via the sublingual or intragastric route together with $H$. pylori lysate in mice [105]. The LT mutant was similar to the cholera toxin in terms of protective immune responses and efficacy. An alternate adjuvant strategy is the use of an engineered chimeric flagellin (H. pylori/E. coli) to activate TLR5. The prophylactically administered vaccine (as boosts given with alum) was reported to significantly reduce the $H$. pylori DNA levels in association with enhanced serum IgG antibody levels [106]. Finally, because $H$. suis is a significant cause of gastric ulcers in pigs, a BALB/c mouse vaccine model was developed against this disease. Whole $H$. suis lysate or recombinant UreB, but not $r N a p A$, 
showed promise in terms of the bacterial colonization when administered prophylactically [107].

\section{Retrospective and new considerations in $\boldsymbol{H}$. pylori vaccine development}

The results of the clinical studies (Table 1) performed to date present a re-evaluation of the understanding of $H$ pylori immunity. Although it must be acknowledged that the mouse model is extremely useful for helping to define differences in the nature of the immune responses to infection and immunization, it may lack predictive ability when designing an efficacious vaccine. Most studies defined protection as a significant reduction in bacterial load, with only occasional reports of sterilizing immunity [108, 109]. Additional evidence revealed that the levels of protection observed in mice might not reflect its use in the human. Based on the data obtained from the primate studies (e.g., rhesus macaques harboring native $H$. pylori infections), one may deduce that in a model of indigenous $H$. pylori infection, vaccines similar to those tested on mice are much less efficacious [110, 111]. In fact, the host response to H. pylori is actively suppressed by regulatory $\mathrm{T}$ (Treg) cells and IL-10-producing Tr1 cells $[49,112]$. In vitro lymphocyte recall assays on infected and non-infected subjects demonstrate comparable responses to $H$. pylori antigen $[112,113]$. Further, depletion of CD25hi T cells led to significant activity in the T cells isolated from $H$. pylori-infected donors [114]. Subsequent experiments have documented that the presence of Treg cells in the infected human stomach might cause a blockage or suppression of Treg cells, and hence, significantly increasing the activity of T-helper cells and gastric inflammation and markedly reducing/eliminating the bacterial load from the stomach $[49,115,116]$. The host gastrointestinal tract inherently suppresses the immune responses to commensal bacteria, thus future strategies might incorporate the mechanisms of limiting Treg cells activity or preferentially activating proinflammatory $\mathrm{T}$ cells that can overcome the activity of Treg cells. In that light, the administration of IL-12 to $H$. felis-infected mice was sufficient to achieve the eradication of the bacteria in the absence of immunization [117]. Finally, although the results have yet to be published, a large-scale phase III of the clinical trial was completed in China to test a prophylactic oral vaccine against the natural acquisition of $H$. pylori [118]. The vaccine was tested on children aged 6-15 years who were negative in terms of H. pylori. The oral vaccine contained the urease B protein subunit, while additional details remain unknown. It was administered in three 15-mg immunization doses, and the children were monitored to determine the rate of natural $H$. pylori infection. Studies in mice indicate that antibodies are sufficient to prevent the infection when present at a challenge sufficiently [119]. Recently, a novel oral vaccine has been constructed against the H. pylori infection in the children. On the basis of the phase III data, the researchers claimed the vaccine as a safe and well immunogenic treatment modality that could prevent the $H$. pylori infection with a high rate (up to $71.8 \%$ ) [120]. To date, almost twenty US patents have been submitted about the different aspects of H. pylori infection from 1997 to 2015 years.

\section{New strategies about $H$. pylori vaccine construction}

Recently, some researchers have focused on the recombinant vaccines with multiple T- and/or B-cell epitopes against $H$. pylori infection. Multi-epitope vaccines that generally composed of $\mathrm{CD}^{+}$and $\mathrm{CD} 8^{+}$epitopes have been examined due to their safety, stability, cost-effective production, and high specificity. However, the main drawback of this approach is the low immunogenicity that is also observed in the oral vaccines [124].

Identifying and using the protective antigens and virulence factors is another approach for designing vaccines

Table 1 Clinical trials for vaccine efficacy against $H$. pylori

\begin{tabular}{|c|c|c|c|c|c|c|c|}
\hline References & Year & Route & Antigens & Adjuvant & Timing & Challenge & Result \\
\hline [121] & 1999 & Oral & Urease & LT mutant & Therapeutic & Natural & $\begin{array}{l}\text { Significant reduction in bacterial } \\
\text { load in some vaccine groups }\end{array}$ \\
\hline$[122]$ & 2001 & Oral & Whole cell & LT mutant & Therapeutic & Natural & No clearance \\
\hline [123] & 2008 & Oral & Urease or Hp0231 & $\begin{array}{l}\text { Salmonella enterica } \\
\text { serovar Typhi } \\
\text { Ty21a }\end{array}$ & Prophylactic & Experimental & $\begin{array}{l}\text { Some clearance in both vaccine and } \\
\text { control groups }\end{array}$ \\
\hline [96] & 2012 & Intramuscular & CagA VacA Nap & Alum & Prophylactic & Experimental & $\begin{array}{l}\text { Clearance equivalent between vac- } \\
\text { cine and controls groups }\end{array}$ \\
\hline [118] & 2014 & Oral & Urease & Undisclosed & Prophylactic & Natural & Efficacy, $72 \%$ \\
\hline [120] & 2015 & Oral & Urease & Undisclosed & Prophylactic & Experimental & $\begin{array}{l}\text { Significant prevention of the infec- } \\
\text { tion in the children }\end{array}$ \\
\hline
\end{tabular}


against developing cancers and $H$. pylori infection. Different virulence factors have been used for constructing high effective vaccines against $H$. pylori, including urease (UreA and UreB), vacuolating cytotoxin (VacA), neutrophil-activating protein (NapA), CagA, heat shock proteins (Hsps), and different types of outer membrane protein (Omps) [125, 126]. A chimeric vaccine, consisting of UreA and $U r e B$, was constructed and expressed in E. coli. The recombinant protein was purified and used for intragastric vaccination of Mongolian gerbils [127] and C57BL/6 mice [128], which showed partial inhibition of $H$. pylori infection. Regarding the limited success of intragastric vaccination, some researchers have focused on new platforms for an oral administration of the vaccines, including a vaccine expressed in Lactococcus lactis NZ9000, and the spores of Bacillus subtilis. Because the bacteria show very low survival in the gastrointestinal tract, the antigen-based vaccines, which was expressed cytoplasmically, could be released in this tract resulting in the minimization of the H. pylori infection [125].

Microalgae, as a group of photosynthetic microorganisms, have unique characteristics (fast growth rate and simple and cost-effective cultivation procedure) [129] and can be used as edible vaccines. The cell-wall polysaccharides of different microalgae, which might present a natural encapsulation for the recombinant proteins and protect them within the harsh conditions of the stomach and intestine and act as an effective adjuvant for boosting the immune system [130,131].

\section{Conclusion}

During $H$. pylori-induced chronic inflammation and subsequent carcinogenesis, various bacterial, host, and environmental factors may be associated in the emergence of inflammation and progression of the disease. While having $\mathrm{H}$. pylori in over $50 \%$ of the world's population, only $2 \%$ of the infected cases develop GC and fewer develop a MALT lymphoma. Given such variable threat of $H$. pylori infection-mediated malignancy, what are the important factors or co-factors involved in dictating which individuals with $H$. Pylori infection will undergo $H$. pylori-induced gastric transformation? Some of the variability in outcome can be correlated with the bacterial strain specificity, host genetic susceptibility, and the type of immune response elicited in the infected host.

Acknowledgements This study was financially supported by the Research Center for Pharmaceutical Nanotechnology (RCPN) at Tabriz University of Medical Sciences (Grant \#: RCPN-94010). This project is part of Ph.D. thesis (No. 94/010/156/3) conducted at RCPN.

\section{Compliance with ethical standards}

Ethical approval There is none to be declared.

Conflict of interest The authors declare no competing interests.

\section{References}

1. Linz B, Balloux F, Moodley Y, Manica A, Liu H, Roumagnac $\mathrm{P}$, et al. An African origin for the intimate association between humans and Helicobacter pylori. Nature. 2007;445(7130):915-8.

2. Marshall B, Warren JR. Unidentified curved bacilli in the stomach of patients with gastritis and peptic ulceration. Lancet. 1984;323(8390):1311-5.

3. Parkin DM, Bray F, Ferlay J, Pisani P. Global cancer statistics, 2002. CA Cancer J Clin. 2005;55(2):74-108.

4. Venneman K, Huybrechts I, Gunter MJ, Vandendaele L, Herrero $\mathrm{R}$, Van Herck K. The epidemiology of Helicobacter pylori infection in Europe and the impact of lifestyle on its natural evolution toward stomach cancer after infection: a systematic review. Helicobacteria. 2018;23:e12483.

5. Quiros RM, Bui CL. Multidisciplinary approach to esophageal and gastric cancer. Surg Clin N Am. 2009;89(1):79-96.

6. Du M, Atherton J. Molecular subtyping of gastric MALT lymphomas: implications for prognosis and management. Gut. 2006;55(6):886-93.

7. Oh S, Kim N, Oh DH, Bang S-M, Choi YJ, Lee JY, et al. Concurrent gastric and pulmonary mucosa-associated lymphoid tissue lymphomas with pre-existing intrinsic chronic inflammation: a case report and a review of the literature. Gut Liver. 2015;9(3):424.

8. Parkin DM. The global health burden of infection-associated cancers in the year 2002. Int J Cancer. 2006;118(12):3030-44.

9. Noto JM, Peek RM Jr. Helicobacter pylori: an overview, Helicobacter species. Berlin: Springer; 2012. pp. 7-10.

10. Kamangar F, Dawsey SM, Blaser MJ, Perez-Perez GI, Pietinen $\mathrm{P}$, Newschaffer CJ, et al. Opposing risks of gastric cardia and noncardia gastric adenocarcinomas associated with Helicobacter pylori seropositivity. J Natl Cancer Inst. 2006;98(20):1445-52.

11. Kamada T, Kurose H, Yamanaka Y, Manabe N, Kusunoki H, Shiotani A, et al. Relationship between gastroesophageal junction adenocarcinoma and Helicobacter pylori infection in Japan. Digestion. 2012;85(4):256-60.

12. Hill P, Rode J. Helicobacter pylori in ectopic gastric mucosa in Meckel's diverticulum. Pathology. 1998;30(1):7-9.

13. Dubois A, Borén T. Helicobacter pylori is invasive and it may be a facultative intracellular organism. Cell Microbiol. 2007;9(5):1108-16.

14. Amieva MR, El-Omar EM. Host-Bacterial Interactions in Helicobacter pylori Infection. Gastroenterology. 2008;134(1):306-23.

15. Sycuro LK, Pincus Z, Gutierrez KD, Biboy J, Stern CA, Vollmer $\mathrm{W}$, et al. Peptidoglycan crosslinking relaxation promotes Helicobacter pylori's helical shape and stomach colonization. Cell. 2010;141(5):822-33.

16. Falush D. Traces of human migrations in Helicobacter pylori populations. Science. 2003;299:1582-5.

17. Tomb J-F, White O, Kerlavage AR, Clayton RA, Sutton GG, Fleischmann RD, et al. The complete genome sequence of the gastric pathogen Helicobacter pylori. Nature. 1997;388(6642):539-47.

18. McClain MS, Shaffer CL, Israel DA, Peek RM, Cover TL. Genome sequence analysis of Helicobacter pylori strains 
associated with gastric ulceration and gastric cancer. BMC Genom. 2009;10(1):3.

19. Thiberge J-M, Boursaux-Eude C, Lehours P, Dillies M-A, Creno S, Coppée J-Y, et al. From array-based hybridization of Helicobacter pylori isolates to the complete genome sequence of an isolate associated with MALT lymphoma. BMC Genom. 2010;11(1):368.

20. Alm RA, Ling L-SL, Moir DT, King BL, Brown ED, Doig PC, et al. Genomic-sequence comparison of two unrelated isolates of the human gastric pathogen Helicobacter pylori. Nature. 1999;397(6715):176-80.

21. Baltrus DA, Amieva MR, Covacci A, Lowe TM, Merrell DS, Ottemann KM, et al. The complete genome sequence of Helicobacter pylori strain G27. J Bacteriol. 2009;191(1):447-8.

22. Oh JD, Kling-Bäckhed H, Giannakis M, Xu J, Fulton RS, Fulton LA, et al. The complete genome sequence of a chronic atrophic gastritis Helicobacter pylori strain: evolution during disease progression. Proc Natl Acad Sci USA. 2006;103(26):9999-10004.

23. Israel DA, Salama N, Krishna U, Rieger UM, Atherton JC, Falkow $\mathrm{S}$, et al. Helicobacter pylori genetic diversity within the gastric niche of a single human host. Proc Natl Acad Sci USA. 2001;98(25):14625-30.

24. Fahimi F, Tohidkia MR, Fouladi M, Aghabeygi R, Samadi N, Omidi Y. Pleiotropic cytotoxicity of VacA toxin in host cells and its impact on immunotherapy. Bioimpacts. 2017;7(1):59-71. https://doi.org/10.15171/bi.2017.08.

25. Higashi H, Yokoyama K, Fujii Y, Ren S, Yuasa H, Saadat I, et al. EPIYA motif is a membrane-targeting signal of Helicobacter pylori virulence factor CagA in mammalian cells. J Biol Chem. 2005;280(24):23130-7.

26. Cover TL, Blaser M. Purification and characterization of the vacuolating toxin from Helicobacter pylori. J Biol Chem. 1992;267(15):10570-5.

27. Basso D, Zambon CF, Letley DP, Stranges A, Marchet A, Rhead JL, et al. Clinical Relevance of Helicobacter pylori cagA and vacA Gene Polymorphisms. Gastroenterology. 2008;135(1):91-9.

28. Sharma CM, Hoffmann S, Darfeuille F, Reignier J, Findeiß S, Sittka A, et al. The primary transcriptome of the major human pathogen Helicobacter pylori. Nature. 2010;464(7286):250-5.

29. Wang F, Meng W, Wang B, Qiao L. Helicobacter pyloriinduced gastric inflammation and gastric cancer. Cancer Lett. 2014;345(2):196-202.

30. Müller A. Multistep activation of the Helicobacter pylori effector CagA. J Clin Invest. 2012;122(4):1192.

31. Jiménez-Soto LF, Kutter S, Sewald X, Ertl C, Weiss E, Kapp U, et al. Helicobacter pylori type IV secretion apparatus exploits $\beta 1$ integrin in a novel RGD-independent manner. PLoS Pathog. 2009;5(12):e1000684.

32. Mueller D, Tegtmeyer N, Brandt S, Yamaoka Y, De Poire E, Sgouras D, et al. c-Src and c-Abl kinases control hierarchic phosphorylation and function of the CagA effector protein in Western and East Asian Helicobacter pylori strains. J Clin Invest. 2012;122(4):1553.

33. Xu X, Liu Z, Fang M, Yu H, Liang X, Li X, et al. Helicobacter pylori CagA induces ornithine decarboxylase upregulation via Src/MEK/ERK/c-Myc pathway: implication for progression of gastric diseases. Exp Biol Med. 2012;237(4):435-41.

34. Amin A, Qadri RA, Lone G. Progression and metastasis of lung cancer-a study of predominant cellular interactions in tumor microenvironment. PhD Dissertation. 2016.

35. Boquet P, Ricci V. Intoxication strategy of Helicobacter pylori VacA toxin. Trends Microbiol. 2012;20(4):165-74.

36. Rassow J, Meinecke M. Helicobacter pylori VacA: a new perspective on an invasive chloride channel. Microbes Infect. 2012;14(12):1026-33.
37. Jain P, Luo Z-Q, Blanke SR. Helicobacter pylori vacuolating cytotoxin $\mathrm{A}$ ( VacA) engages the mitochondrial fission machinery to induce host cell death. Proc Natl Acad Sci. 2011;108(38):16032-7.

38. Palframan SL, Kwok T, Gabriel K. Vacuolating cytotoxin A (VacA), a key toxin for Helicobacter pylori pathogenesis. Front Cell Infect Microbiol. 2012;2:92.

39. Raju D, Hussey S, Ang M, Terebiznik MR, Sibony M, Galindo-Mata E, et al. Vacuolating cytotoxin and variants in Atg16L1 that disrupt autophagy promote Helicobacter pylori infection in humans. Gastroenterology. 2012;142(5):1160-71.

40. Lamb A, Chen LF. Role of the Helicobacter pylori-induced inflammatory response in the development of gastric cancer. $\mathbf{J}$ Cell Biochem. 2013;114(3):491-7.

41. Hoffmann W. Stem cells, self-renewal and cancer of the gastric epithelium. Curr Med Chem. 2012;19(35):5975-83.

42. Yasui W, Sentani K, Sakamoto N, Anami K, Naito Y, Oue N. Molecular pathology of gastric cancer: research and practice. Pathol Res Pract. 2011;207(10):608-12.

43. Xu G, Shen J, Yang XO, Sasahara M, Su X. Cancer stem cells: the 'heartbeat' of gastric cancer. J Gastroenterol. 2013;48(7):781-97.

44. Ferrand J, Lehours P, Schmid-Alliana A, Mégraud F, Varon C. Helicobacter pylori infection of gastrointestinal epithelial cells in vitro induces mesenchymal stem cell migration through an NF-kB-dependent pathway. PLoS One. 2011;6(12):e29007.

45. Varon C, Dubus P, Mazurier F, Asencio C, Chambonnier L, Ferrand $\mathrm{J}$, et al. Helicobacter pylori infection recruits bone marrow derived cells that participate in gastric preneoplasia in mice. Gastroenterology. 2012;142(2):281-91.

46. Pollard JW. Tumour-educated macrophages promote tumour progression and metastasis. Nat Rev Cancer. 2004;4(1):71.

47. Preston-Martin S, Pike MC, Ross RK, Jones PA, Henderson BE. Increased cell division as a cause of human cancer. Cancer Res. 1990;50(23):7415-21.

48. Moss SF, Blaser MJ. Mechanisms of disease: inflammation and the origins of cancer. Nat Clin Pract Oncol. 2005;2(2):90-7.

49. Anderson KM, Czinn SJ, Redline RW, Blanchard TG. Induction of CTLA-4-mediated anergy contributes to persistent colonization in the murine model of gastric Helicobacter pylori infection. J Immunol. 2006;176(9):5306-13.

50. Polk DB, Peek RM Jr. Helicobacter pylori: gastric cancer and beyond. Nat Rev Cancer. 2010;10(6):403.

51. Wei J, O'Brien D, Vilgelm A, Piazuelo MB, Correa P, Washington MK, et al. Interaction of Helicobacter pylori with gastric epithelial cells is mediated by the p53 protein family. Gastroenterology. 2008;134(5):1412-23.

52. Shin CM, Kim N, Jung Y, Park JH, Kang GH, Kim JS, et al. Role of Helicobacter pylori infection in aberrant DNA methylation along multistep gastric carcinogenesis. Cancer Sci. 2010;101(6):1337-46.

53. Hamilton JP, Meltzer SJ. A review of the genomics of gastric cancer. Clin Gastroenterol Hepatol. 2006;4(4):416-25.

54. Chan A, Peng J, Lam S, Lai K, Yuen M, Cheung H, et al. Eradication of Helicobacter pylori infection reverses E-cadherin promoter hypermethylation. Gut. 2006;55(4):463-8.

55. Sepulveda AR, Yao Y, Yan W, Park DI, Kim JJ, Gooding W, et al. $\mathrm{CpG}$ methylation and reduced expression of $\mathrm{O}(6)$ methylguanine DNA methyltransferase is associated with Helicobacter pylori infection. Gastroenterology. 2010;138(5):1836-44.

56. Belair C, Darfeuille F, Staedel C. Helicobacter pylori and gastric cancer: possible role of microRNAs in this intimate relationship. Clin Microbiol Infect. 2009;15(9):806-12.

57. Matsushima K, Isomoto H, Inoue N, Nakayama T, Hayashi T, Nakayama M, et al. MicroRNA signatures in Helicobacter pyloriinfected gastric mucosa. Int J Cancer. 2011;128(2):361-70. 
58. Zhang Z, Li Z, Gao C, Chen P, Chen J, Liu W, et al. miR-21 plays a pivotal role in gastric cancer pathogenesis and progression. Lab Invest. 2008;88(12):1358-66.

59. Xiao B, Liu Z, Li B-S, Tang B, Li W, Guo G, et al. Induction of microRNA-155 during Helicobacter pylori infection and its negative regulatory role in the inflammatory response. J Infect Dis. 2009;200(6):916-25.

60. Fehri LF, Koch M, Belogolova E, Khalil H, Bolz C, Kalali B, et al. Helicobacter pylori induces miR-155 in T cells in a cAMPFoxp3-dependent manner. PLoS One. 2010;5(3):e9500.

61. Correa P, Haenszel W, Cuello C, Tannenbaum S, Archer M. A model for gastric cancer epidemiology. Lancet. 1975;306(7924):58-60.

62. Sanduleanu S, Jonkers D, De Bruine A, Hameeteman W, Stockbrügger R. Changes in gastric mucosa and luminal environment during acid-suppressive therapy: a review in depth. Dig Liver Dis. 2001;33(8):707-19.

63. Hansson L-E, Nyrén O, Hsing AW, Bergström R, Josefsson S, Chow W-H, et al. The risk of stomach cancer in patients with gastric or duodenal ulcer disease. N Engl J Med. 1996;335(4):242-9.

64. Calam J. The somatostatin-gastrin link of Helicobacter pylori infection. Ann Med. 1995;27(5):569-73.

65. Hahm KB, Lee KM, Kim YB, Hong WS, Lee WH, Han SU, et al. Conditional loss of TGF- $\beta$ signalling leads to increased susceptibility to gastrointestinal carcinogenesis in mice. Aliment Pharmacol Ther. 2002;16:115-27. https://doi. org/10.1046/j.1365-2036.16.s2.3.x.

66. Wei J, Nagy TA, Vilgelm A, Zaika E, Ogden SR, RomeroGallo J, et al. Regulation of p53 tumor suppressor by Helicobacter pylori in gastric epithelial cells. Gastroenterology. 2010;139(4):1333-43. e4.

67. Handa O, Naito Y, Yoshikawa T. Redox biology and gastric carcinogenesis: the role of Helicobacter pylori. Redox Rep. 2011;16(1):1-7.

68. Tsugawa H, Suzuki H, Saya H, Hatakeyama M, Hirayama T, Hirata K, et al. Reactive oxygen species-induced autophagic degradation of Helicobacter pylori CagA is specifically suppressed in cancer stem-like cells. Cell Host Microb. 2012;12(6):764-77.

69. Mattsson A, Lönroth H, Quiding-Järbrink M, Svennerholm A-M. Induction of B cell responses in the stomach of Helicobacter pylori-infected subjects after oral cholera vaccination. J Clin Invest. 1998;102(1):51.

70. Pappo J, Thomas W, Kabok Z, Taylor N, Murphy J, Fox J. Effect of oral immunization with recombinant urease on murine Helicobacter felis gastritis. Infect Immun. 1995;63(4):1246-52.

71. Ilver D, Arnqvist A, Ögren J, Frick I-M, Kersulyte D, Incecik ET, et al. Helicobacter pylori adhesin binding fucosylated histo-blood group antigens revealed by retagging. Science. 1998;279(5349):373-7.

72. Su B, Hellström PM, Rubio C, Çelik J, Granström M, Normark S. Type I Helicobacter pylori shows Lewisb-independent adherence to gastric cells requiring de novo protein synthesis in both host and bacteria. J Infect Dis. 1998;178(5):1379-90.

73. Su B, Johansson S, Fällman M, Patarroyo M, Granström M, Normark S. Signal transduction-mediated adherence and entry of Helicobacter pylori into cultured cells. Gastroenterology. 1999;117(3):595-604.

74. Syder AJ, Guruge JL, Li Q, Hu Y, Oleksiewicz CM, Lorenz RG, et al. Helicobacter pylori attaches to NeuAc $\alpha 2,3 \mathrm{Gal} \beta 1,4$ glycoconjugates produced in the stomach of transgenic mice lacking parietal cells. Mol Cell. 1999;3(3):263-74.

75. Odenbreit S, Püls J, Sedlmaier B, Gerland E, Fischer W, Haas R. Translocation of Helicobacter pylori CagA into gastric epithelial cells by type IV secretion. Science. 2000;287(5457):1497-500.

76. Segal ED, Falkow S, Tompkins L. Helicobacter pylori attachment to gastric cells induces cytoskeletal rearrangements and tyrosine phosphorylation of host cell proteins. Proc Natl Acad Sci U S A. 1996;93(3):1259-64.

77. Segal ED, Lange C, Covacci A, Tompkins L, Falkow S. Induction of host signal transduction pathways by Helicobacter pylori. Proc Natl Acad Sci USA. 1997;94(14):7595-9.

78. Keates S, Hitti YS, Upton M, Kelly CP. Helicobacter pylori infection activates NF-kappa B in gastric epithelial cells. Gastroenterology. 1997;113(4):1099-109.

79. Ibraghimov A, Pappo J. The immune response against Helicobacter pylor - a direct linkage to the development of gastroduodenal disease. Microb Infect. 2000;2(9):1073-7.

80. Crowe SE, Alvarez L, Dytoc M, Hunt RH, Muller M, Sherman P, et al. Expression of interleukin 8 and CD54 by human gastric epithelium after Helicobacter pylori infection in vitro. Gastroenterology. 1995;108(1):65-74.

81. Hansen PS, Go MF, Varming K, Andersen LP, Genta RM, Graham DY, et al. Proinflammatory activation of neutrophils and monocytes by Helicobacter pylori in patients with different clinical presentations. Infect Immun. 1999;67(6):3171-4.

82. Hatz RA, Rieder G, Stolte M, Bayerdorffer E, Meimarakis G, Schildberg F, et al. Pattern of adhesion molecule expression on vascular endothelium in Helicobacter pylori-associated antral gastritis. Gastroenterology. 1997;112(6):1908-19.

83. Ye G, Barrera C, Fan X, Gourley WK, Crowe SE, Ernst PB, et al. Expression of B7-1 and B7-2 costimulatory molecules by human gastric epithelial cells: potential role in CD4 $+\mathrm{T}$ cell activation during Helicobacter pylori infection. J Clin Invest. 1997;99(7):1628.

84. Engstrand L, Scheynius A, Påhlson C, Grimelius L, Schwan A, Gustavsson S. Association of Campylobacter pylori with induced expression of class II transplantation antigens on gastric epithelial cells. Infect Immun. 1989;57(3):827-32.

85. Wee A, Teh M, Kang J. Association of Helicobacter pylori with HLA-DR antigen expression in gastritis. J Clin Pathol. 1992;45(1):30-3.

86. Fan X, Crowe SE, Behar S, Gunasena H, Ye G, Haeberle H, et al. The effect of class II major histocompatibility complex expression on adherence of Helicobacter pylori and induction of apoptosis in gastric epithelial cells: a mechanism for T helper cell type 1-mediated damage. J Exp Med. 1998;187(10):1659-69.

87. Blaser MJ. Ecology of Helicobacter pylori in the human stomach. J Clin Invest. 1997;100(4):759.

88. Knipp U, Birkholz S, Kaup W, Opferkuch W. Partial characterization of a cell proliferation-inhibiting protein produced by Helicobacter pylori. Infect Immun. 1996;64(9):3491-6.

89. Luzza F, Parrello T, Monteleone G, Sebkova L, Imeneo M, Vecchia A, et al. Changes in the mucosal expression of interleukin 15 in Helicobacter pylori-associated gastritis. FEMS Immunol Med Microbiol. 1999;24(2):233-8.

90. Molinari M, Salio M, Galli C, Norais N, Rappuoli R, Lanzavecchia A, et al. Selective inhibition of Ii-dependent antigen presentation by Helicobacter pylori toxin VacA. J Exp Med. 1998;187(1):135-40.

91. Wang J, Brooks EG, Bamford KB, Denning TL, Pappo J, Ernst PB. Negative selection of $\mathrm{T}$ cells by Helicobacter pylori as a model for bacterial strain selection by immune evasion. J Immunol. 2001;167(2):926-34.

92. Shi Y, Liu XF, Zhuang Y, Zhang JY, Liu T, Yin Z, et al. Helicobacter pylori-induced Th17 responses modulate Th1 cell responses, benefit bacterial growth, and contribute to pathology in mice. J Immunol. 2010;184(9):5121-9. https://doi. org/10.4049/jimmunol.0901115.

93. Kronsteiner B, Bassaganya-Riera J, Philipson C, Viladomiu M, Carbo A, Pedragosa M, et al. Helicobacter pylori infection in a pig model is dominated by Th1 and cytotoxic CD $8+\mathrm{T}$ cell 
responses. Infect Immun. 2013;81(10):3803-13. https://doi. org/10.1128/IAI.00660-13.

94. Mookerjee A, Graciotti M, Kandalaft L. A cancer vaccine with dendritic cells differentiated with GM-CSF and IFNa and pulsed with a squaric acid treated cell lysate improves $\mathrm{T}$ cell priming and tumor growth control in a mouse model. Bioimpacts. 2018;8(4):243-52.

95. Koch M, Meyer TF, Moss SF. Inflammation, immunity, vaccines for Helicobacter pylori infection. Helicobacter. 2013;18(s1):18-23.

96. Malfertheiner P, Selgrad M, Wex T, Bornschein J, Palla E, Del Giudice G, et al. 1047 efficacy of an investigational recombinant antigen based vaccine against a CagA $H$. pylori infectious challenge in healthy volunteers. Gastroenterology. 2012;142(5):-184.

97. Chen J, Lin M, Li N, Lin L, She F. Therapeutic vaccination with Salmonella-delivered codon-optimized outer inflammatory protein DNA vaccine enhances protection in Helicobacter pylori infected mice. Vaccine. 2012;30(36):5310-5.

98. Altman E, Chandan V, Harrison BA, Veloso-Pita R, Li J, KuoLee $\mathrm{R}$, et al. Design and immunological properties of Helicobacter pylori glycoconjugates based on a truncated lipopolysaccharide lacking Lewis antigen and comprising an $\alpha-1,6$-glucan chain. Vaccine. 2012;30(50):7332-41.

99. O'Riordan AA, Morales VA, Mulligan L, Faheem N, Windle HJ, Kelleher DP. Alkyl hydroperoxide reductase: a candidate Helicobacter pylori vaccine. Vaccine. 2012;30(26):3876-84.

100. Stent A, Every AL, Ng GZ, Chionh YT, Ong LS, Edwards SJ, et al. Helicobacter pylori thiolperoxidase as a protective antigen in single-and multi-component vaccines. Vaccine. 2012;30(50):7214-20.

101. Li Y, Jiang Y, Xi Y, Zhang L, Luo J, He D, et al. Identification and characterization of $\mathrm{H}-2 \mathrm{~d}$ restricted $\mathrm{CD} 4+\mathrm{T}$ cell epitopes on Lpp20 of Helicobacter pylori. BMC Immunol. 2012;13(1):1.

102. Yang W-C, Chen L, Li H-B, Li B, Hu J, Zhang J-Y, et al. Identification of two novel immunodominant UreB CD4 $+\mathrm{T}$ cell epitopes in Helicobacter pylori infected subjects. Vaccine. 2013;31(8):1204-9.

103. Li H-B, Zhang J-Y, He Y-F, Chen L, Li B, Liu K-Y, et al. Systemic immunization with an epitope-based vaccine elicits a Th1biased response and provides protection against Helicobacter pylori in mice. Vaccine. 2012;31(1):120-6.

104. Guo L, Liu K, Xu G, Li X, Tu J, Tang F, et al. Prophylactic and therapeutic efficacy of the epitope vaccine CTB-UA against Helicobacter pylori infection in a BALB/c mice model. Appl Microbiol Biotechnol. 2012;95(6):1437-44.

105. Ottsjö LS, Flach C-F, Clements J, Holmgren J, Raghavan S. A double mutant heat-labile toxin from Escherichia coli, LT (R192G/L211A), is an effective mucosal adjuvant for vaccination against Helicobacter pylori infection. Infect Immun. 2013;81(5):1532-40.

106. Mori J, Vranac T, Smrekar B, Černilec M, Šerbec V, Horvat S, et al. Chimeric flagellin as the self-adjuvanting antigen for the activation of immune response against Helicobacter pylori. Vaccine. 2012;30(40):5856-63.

107. Vermoote M, Van Steendam K, Flahou B, Smet A, Pasmans F, Glibert P, et al. Immunization with the immunodominant Helicobacter suis urease subunit $\mathrm{B}$ induces partial protection against H. suis infection in a mouse model. Vet Res. 2012;43(1):1.

108. Garhart CA, Redline RW, Nedrud JG, Czinn SJ. Clearance of Helicobacter pylori infection and resolution of postimmunization gastritis in a kinetic study of prophylactically immunized mice. Infect Immun. 2002;70(7):3529-38.

109. Kleanthous H, Tibbitts TJ, Gray HL, Myers GA, Lee CK, Ermak $\mathrm{TH}$, et al. Sterilizing immunity against experimental Helicobacter pylori infection is challenge-strain dependent. Vaccine. 2001;19(32):4883-95.
110. Dubois A, Lee CK, Fiala N, Kleanthous H, Mehlman PT, Monath T. Immunization against natural Helicobacter pylori infection in nonhuman primates. Infect Immun. 1998;66(9):4340-6.

111. Solnick JV, Canfield DR, Hansen LM, Torabian SZ. Immunization with recombinant Helicobacter pylori urease in specific-pathogen-free rhesus monkeys (Macaca mulatta). Infect Immun. 2000;68(5):2560-5.

112. Sayi A, Kohler E, Toller IM, Flavell RA, Müller W, Roers A, et al. TLR-2-activated B cells suppress Helicobacter-induced preneoplastic gastric immunopathology by inducing $\mathrm{T}$ regulatory-1 cells. J Immunol. 2011;186(2):878-90.

113. Sharma S, Miller G, PEREZ-PEREZ G, Gupta R, Blaser M. Humoral and cellular immune recognition of Helicobacter pylori proteins are not concordant. J Clin Exp Immunol. 1994;97(1):126-32.

114. Lundgren A, Suri-Payer E, Enarsson K, Svennerholm A-M, Lundin BS. Helicobacter pylori-specific CD4 + CD25high regulatory $\mathrm{T}$ cells suppress memory T-cell responses to $H$. pylori in infected individuals. Infect Immun. 2003;71(4):1755-62.

115. Rad R, Brenner L, Bauer S, Schwendy S, Layland L, da Costa $\mathrm{CP}$, et al. CD25+/Foxp3 + T cells regulate gastric inflammation and Helicobacter pylori colonization in vivo. Gastroenterology. 2006;131(2):525-37.

116. Raghavan S, Suri-Payer E, Holmgren J. Antigen-specific in vitro suppression of murine Helicobacter pylori-reactive immunopathological $\mathrm{T}$ cells by $\mathrm{CD} 4+\mathrm{CD} 25+$ regulatory $\mathrm{T}$ cells. Scand J Immunol. 2004;60(1-2):82-8.

117. Ding H, Nedrud JG, Blanchard TG, Zagorski BM, Li G, Shiu $\mathrm{J}$, et al. Th1-mediated immunity against Helicobacter pylori can compensate for lack of Th17 cells and can protect mice in the absence of immunization. PloS One. 2013;8(7):e69384.

118. Blanchard TG, Czinn SJ. Current status and prospects for a Helicobacter pylori vaccine. Gastroenterol Clin N Am. 2015;44(3):677-89.

119. Blanchard TG, Czinn SJ, Maurer R, Thomas WD, Soman G, Nedrud JG. Urease-specific monoclonal antibodies prevent Helicobacter felis infection in mice. Infect Immun. 1995;63(4):1394-9.

120. Zeng M, Mao X-H, Li J-X, Tong W-D, Wang B, Zhang Y-J, et al. Efficacy, safety, and immunogenicity of an oral recombinant Helicobacter pylori vaccine in children in China: a randomised, double-blind, placebo-controlled, phase 3 trial. Lancet. 2015;386(10002):1457-64.

121. Michetti P, Kreiss C, Kotloff KL, Porta N, Blanco JL, Bachmann D, et al. Oral immunization with urease and Escherichia coli heat-labile enterotoxin is safe and immunogenic in Helicobacter pylori-infected adults. Gastroenterology. 1999;116(4):804-12.

122. Kotloff KL, Sztein MB, Wasserman SS, Losonsky GA, DiLorenzo SC, Walker RI. Safety and immunogenicity of oral inactivated whole-cell Helicobacter pylori vaccine with adjuvant among volunteers with or without subclinical infection. Infect Immun. 2001;69(6):3581-90.

123. Aebischer T, Bumann D, Epple H-J, Metzger W, Schneider T, Cherepnev $\mathrm{G}$, et al. Correlation of $\mathrm{T}$ cell response and bacterial clearance in human volunteers challenged with Helicobacter pylori revealed by randomised controlled vaccination with Ty21a-based Salmonella vaccines. Gut. 2008;57(8):1065-72.

124. Walduck AK, Becher D. Leptin, CD4 + Treg and the prospects for vaccination against $H$. pylori infection. Front Immunol. 2012;3:316.

125. Zhang H-x, Qiu Y-y, Zhao Y-h, Liu X-t, Liu M, Yu A-1. Immunogenicity of oral vaccination with Lactococcus lactis derived vaccine candidate antigen (UreB) of Helicobacter pylori fused with the human interleukin 2 as adjuvant. Mol Cell Probes. 2014;28(1):25-30. 
126. Sarfo FS, Eberhardt KA, Dompreh A, Kuffour EO, Soltau M, Schachscheider M, et al. Helicobacter pylori infection is associated with higher CD4 T cell counts and lower HIV-1 viral loads in ART-naïve HIV-positive patients in Ghana. PloS One. 2015;10(11):e0143388.

127. Guo L, Yang H, Tang F, Yin R, Liu H, Gong X, et al. Oral immunization with a multivalent epitope-based vaccine, based on NAP, Urease, HSP60, and HpaA, provides therapeutic effect on $H$. pylori infection in mongolian gerbils. Front Cell Infect Microbiol. 2017;7:349.

128. Wang X, Willen R, Svensson M, Ljungh Å, WadstrÖm T. Twoyear follow-up of Helicobacter pylori infection in C57BL/6 and Balb/cA mice. Apmis. 2003;111(4):514-22.
129. Dehghani J, Movafeghi A, Barzegari A, Barar J. Efficient and stable transformation of Dunaliella pseudosalina by 3 strains of Agrobacterium tumefaciens. Bioimpacts. 2017;7(4):247-54. https://doi.org/10.15171/bi.2017.29.

130. Specht EA, Mayfield SP. Algae-based oral recombinant vaccines. Front Microbiol. 2014;5:60.

131. Barzegari A, Saeedi N, Zarredar H, Barar J, Omidi Y. The search for a promising cell factory system for production of edible vaccine: spirulina as a robust alternate to plants. Hum Vaccin Immunother. 2014;10(8):2497-502. 